\title{
Using research to influence family services and policies: issues and challenges
}

\author{
Sarah Morton,' David Phipps and Sandra Nutley
}

\section{Introduction}

There is growing national and international interest in the ways that research might influence policy and practice (Mullen, 2005; Nutley et al, 2007; Alexanderson et al, 2009; Ouimet et al, 2009; Widmer, 2009; Nutley et al, 2011). The articles in this Open Space section discuss how research is used to inform policy and practice development and how this relationship can be enhanced. They build on a dialogue at the Centre for Research on Families and Relationships' (CRFR) national conference in November 2011, which considered the impact of social research. CRFR has been at the forefront of developing approaches to knowledge exchange on families and relationships research for the last 10 years (Morton and Nutley,2011). The conference aimed to highlight interesting and innovative work and create a dialogue around ongoing issues and challenges.

This introductory article considers some of the key issues and challenges around using research and it draws on presentations that the authors made at the conference. It begins by outlining what research use means and it then offers some emerging lessons about how such use can be improved. This is followed by reflections on how these lessons relate to the experiences of two units dedicated to improving research use: CRFR (Scotland) and the Knowledge Mobilization (KMb) Unit at York University (Toronto, Canada). Then the contribution of the other articles in the Open Space section to our understanding of the complexities of research use is discussed, and finally the future challenges are considered.

This article reflects the authors' perspectives and experiences. Sarah Morton has worked as a knowledge exchange practitioner for 10 years, she is co-director (Knowledge Exchange) at CRFR and has recently been investigating how research impact can be assessed. David Phipps is the director of Research Services \& Knowledge Exchange atYork University (Toronto, Canada) where he manages all research grants and contracts and has established the pioneering KMb Unit. Sandra Nutley is director of the Research Unit for Research Utilisation (www.ruru.ac.uk) and she is known internationally for her work on research use and evidence-based policy and practice.

\section{What it means to use research}

There has been much discussion and debate about the ways research is used in policy and practice (eg, Rein, 1976; Weiss, 1979; Nutley et al, 2007). Weiss's (1979) often-quoted typology of research use suggests that research is used in at least three different ways. Occasionally, research is used directly and instrumentally - when research knowledge is used directly to change policy and practice, either because the research evidence is so strong and compelling that it drives change or because policy makers

Families, Relationships and Societies • vol I • no 2 • 2012 • 243-53

http://dx.doi.org/| 0.1332/2046743 I 2 X645547 
search for research that helps them to understand and address social problems. More commonly, research has a more indirect influence on the way people think about an issue (the conceptual use of research). This may occur as a result of researchers directly sharing their findings or it can be the effect of a more general percolation of research ideas via the media and wider discussions. Finally, research can also be used politically or symbolically to bolster a decision that was reached on other grounds.

Thinking about these three main forms of research use (instrumental, conceptual and political) as distinct categories is not always helpful. Nutley et al (2007) have suggested that we consider instrumental and conceptual uses of research on a continuum (see Figure 1). While it might be tempting to think that the arrow in this figure just points from the left to right - and some models of the research use process suggest that awareness and attitude change always precede behaviour change - there are examples where practice change comes first and only later do practitioners change their attitudes and ways of thinking about an issue (eg, changes in childcare practice due to the introduction of new, research-based regulations).

\section{Figure I:A research use continuum}

\begin{tabular}{|c|c|c|c|}
\hline \multicolumn{3}{|c|}{ MORE CONCEPTUAL USES } & INSTRUMENTAL USES \\
\hline Awareness & $\begin{array}{l}\text { Knowledge and } \\
\text { understanding }\end{array}$ & $\begin{array}{l}\text { Changing attitudes, } \\
\text { perceptions, ideas }\end{array}$ & $\begin{array}{l}\text { Practice and } \\
\text { policy changes }\end{array}$ \\
\hline
\end{tabular}

There is often frustration on the part of researchers that policy makers and practitioners seem to base decisions on factors other than evidence. In this scenario, if research is used at all it is used politically and symbolically at best. Phil Davies, former deputy chief social researcher at the Cabinet Office, has suggested that politicians listen to the media and cab drivers before they take account of research findings (Davies, 2007). However, such an impression tends to underplay the somewhat hidden influence of research over time. There are many areas of policy and practice where research has been an important influence on the way policy has unfolded, for example the increased emphasis on the importance of early years in social policy or the acknowledgement of the crucial role of informal carers in social and health policy. While the political and symbolic use of research may seem uppermost in the short term, in the medium to long term research can have a more diffuse effect on how we think about social problems (what Weiss termed the 'enlightenment' effect of research).

The challenges of research getting used are often characterised by the idea of two communities - policy makers or practitioners in one community, and academic researchers in the other - separated by misunderstandings and a mismatch between research supply and demand due to differences in culture, power, reward systems and operational timescales (Caplan, 1977; Cousins and Simon, 1996). While there is some merit in this two-communities caricature, there are in fact many players in the

Families, Relationships and Societies $・$ vol I • no $2 \cdot 2012 \cdot 243-53$

http://dx.doi.org/ | 0.1332/2046743 | 2 X645547 
research use process (Davies et al, 2008). There are different groups of research users, and research is produced by various types of analyst working in different settings. Furthermore, in between these groups of producers and users, research travels via many other groups and channels, including knowledge exchange fora, the media, campaign groups and regulatory and professional bodies. Not only is this landscape more complex than the two-communities concept would suggest, but also the concept breaks down when researchers and users work together to co-produce and apply research evidence. The implications of this for strategies to improve research use are discussed below.

There is no denying that research use is often patchy and difficult to achieve because the processes of policy and practice change are complex and somewhat ad hoc. Policy making is rarely a rational process involving a sharply delineated event, explicit decisions and known actors, where policies are clearly defined and fixed at the point of implementation. More often it is a messy process of piecemeal decision making involving many actors who muddle through. In these circumstances, policies emerge over time and are only fully shaped through the long process of their implementation. The role of research in this messy, incremental process can be contentious and is often difficult to trace.The implications for researchers who wish to make an impact is that they need to work with many potential research users on an ongoing basis.

\section{Some emerging lessons about effective practices to improve research use}

There is a growing literature on what works to improve research use but empirical evidence is still rather weak and tends to be skewed by the greater prevalence of studies in the healthcare field. However, there is some consensus emerging across the literature (Mitton et al, 2007; Nutley et al, 2007; Ward et al, 2009). In her presentation at the CRFR national conference, Nutley suggested that current thinking can be summarised into seven lessons.

\section{Lesson I: Set realistic ambitions and expectations about research use}

It is more realistic to talk of evidence-informed than evidence-determined policy. Other influences on the policy process, including political and value judgements, are important and legitimate. Social research and evaluation studies rarely provide the definitive word and research users need to interpret findings and integrate them with other forms of context-specific knowledge before they can be applied in policy or practice settings. This interpretation and integration process will reflect those actors' views and judgements and this will undoubtedly lead to further questions about what works and why in what settings. Thus, a cautious, ongoing 'experimental' approach to policy making and practice development is advisable given the uncertainties associated with research findings and their applicability.

Families, Relationships and Societies • vol I • no 2 • 2012 • 243-53

http://dx.doi.org/| 0.1332/2046743 | 2X645547 


\section{Lesson 2: Improve the supply of relevant, accessible and credible evidence but do not stop there}

There is a need for improved research and development strategies to ensure that research addresses issues that are likely to be of interest now and in the future, and that there is sufficient methodological competency and capacity in the analytical community to deliver. Reviewing research and evaluation commissioning processes on an ongoing basis to ensure that they facilitate rather than hinder the production of relevant research would help - for example, do they facilitate the co-production of research knowledge? In addition, there is a lot of research on relevant topics that is in danger of being overlooked and there is often too much unwitting replication of research studies, which does little to expand our knowledge base. Supporting ongoing syntheses of existing studies, which clarify the extent of our existing knowledge and what the main knowledge gaps are, would be helpful, especially if combined with improved registers of evidence and more accessible archives of existing studies.

\section{Lesson 3: Shape - as well as respond to - the demand for evidence in policy and practice settings}

A formal government commitment to an evidence-informed approach is helpful but it by no means guarantees a sympathetic ear for researchers. Both improving the analytical skills of policy makers and practitioners, and addressing the incentives in these contexts to ensure that they are in line with a commitment to evidence use, would help. However, there will be times when it is easier to influence policy and practice debates particularly when the topic in question is relatively high on the agenda of policy makers and practitioners. Rather than just waiting for these 'windows of opportunity' to open up, researchers can work with advocacy organisations to raise the visibility of their areas of concern and get them onto the agenda.

\section{Lesson 4: Develop multifaceted strategies to address the interplay between supply and demand}

Interaction between people tends to be more important than packaged research 'products' in influencing research use. An appreciation of context also has a large bearing on the nature and extent of research use. Research on its own does not create change but it can influence it through interaction with other kinds of knowledge such as practice experience and tacit knowledge. Therefore it makes sense to create a dialogue around research by pulling together a variety of perspectives. This recognises that research use is an interactive, non-linear, social and political process.

Strategies to improve research use need to build on the generic features of effective practices to increase research impact, which have been distilled from the existing literature in the knowledge exchange field (Nutley et al, 2007):

Families, Relationships and Societies $\cdot$ vol I $\cdot$ no $2 \cdot 2012 \cdot 243-53$ 
- research must be translated - adaptation of findings to specific policy and practice contexts;

- enthusiasm of key individuals - personal contact is most effective;

- contextual analysis - understanding and targeting specific barriers to, and enablers of, change;

- credibility - strong evidence from a trusted source, including endorsement from opinion leaders;

- leadership - within research impact settings;

- support - ongoing financial, technical and emotional support;

- integration - of new activities with existing systems and activities.

\section{Lesson 5: Recognise the role of dedicated knowledge broker organisations and networks}

There are things that both researchers and research users can do to improve the use of research. However, increasingly there are dedicated knowledge broker organisations and networks that facilitate the implementation of many of these lessons. These brokers may be funded by government (eg, the Social Care Institute for Excellence), membership based (eg, Research in Practice), funded by universities (eg, the $\mathrm{KMb}$ Unit at York University, Toronto, Canada) or more informal (eg, CRFR's network of researchers and practitioners). Brokers may facilitate the creation, sharing and application of research-based knowledge through providing access to distilled research knowledge, through brokering relationships between researchers and research users and through building the capacity of all actors to interact with one another.

\section{Lesson 6:Target multiple voices to increase opportunities for evidence to become part of policy discourse}

Given the complexities of the policy process and the many actors involved over time, it makes sense to make sure that research feeds into wider political and public debate alongside targeting key policy makers in the existing government. This might be achieved through direct targeting of influential actors, participating in media debates or speaking at policy and practice conferences and seminars. Other opportunities are when governments seek to open up policy processes to multiple voices, such as through consultation processes, deliberative inquiries and citizen juries. This process is challenging for government which is less in control of the agenda, and for researchers who enter the fray as it exposes them to wider contestation and debate.

\section{Lesson 7: Evaluate (knowledge exchange) strategies to improve research use and learn from this}

Knowledge exchange activities are rarely evaluated in any systematic way (particularly outside of the healthcare field) and knowledge exchange is still an immature discipline that is under-theorised, with only limited empirical evidence, and reliant on

Families, Relationships and Societies • vol I • no 2 • 2012 • 243-53

http://dx.doi.org/| 0.1332/2046743 I 2X645547 
underdeveloped evaluation frameworks and tools. Only through improved evaluation and learning will our understanding of effective strategies develop over time.

\section{Reflections from CRFR's and York University's knowledge exchange activities}

CRFR's work reflects some of these key ideas about the processes of effective knowledge exchange (Morton, 2011). It adopts an interactive approach: encouraging and enabling networks of researchers and research users to meet, discuss and develop research via research interest networks, meetings, web-based activities and research advisory groups. Building relationships between researchers and relevant policy makers, practitioners and others over time to foster trust and create shared agendas has been important (eg, there are ongoing collaborations with the Scottish government, the voluntary sector and the National Health Service). CRFR's approach to research creation and dissemination has been open, with freely accessible briefings, open events and web-based communication. The aim has been to respond quickly and positively to the needs of research users and potential partners in small and large organisations.

In order to address some of the challenges of effective knowledge exchange, CRFR has tried to be innovative and to learn from its experiments. The centre has explored different approaches to communication, engagement and action (eg, packaging short messages for political debate in the Why relationships matter booklet (CRFR, 2010); an artist in residence supporting research participants' communication with service providers) and it has developed new ways of linking research to action through specialist projects. Including different voices in its activities has been an important way of reaching out to children, schools and older people. Essential across the work has been the importance of the provision of skilled staff: knowledge exchange specialists, project workers, graphic designers and events managers.

York University's KMb Unit has the sole purpose of making the university's noncommercial research and expertise accessible to non-academic decision makers by supporting co-production methods of research utilisation (Phipps, 2011). Working primarily with non-profit community agencies providing health and human services, many of the lessons learned map well onto the seven lessons above.

One example illustrates a number of the lessons. York Region is home to Canada's fastest-growing immigrant population and the 'Welcome Centre' provides settlement services to immigrant families seeking to settle and integrate into York Region's social, cultural and economic fabric. The Regional Municipality ofYork contacted the $\mathrm{KMb}$ Unit as it was interested in collaborating on an evaluation of the Inclusivity Action Plan.This evaluation not only resulted in an academic publication (Singh and Hynie, 2008) but also provided evidence that informed a decision to expand the Welcome Centre programme. The Municipality invested over CAN $\$ 20$ million to create an additional fourWelcome Centres, creating 86 jobs and providing over 48,000 services to immigrant families across York Region. This research was only one input into a political decision-making process that took a number of years to complete.

This example illustrates that:

Families, Relationships and Societies $・$ vol $1 \cdot$ no $2 \cdot 2012 \cdot 243-53$

http://dx.doi.org/| 0.1332/204674312X645547 
- research was only one component of the political decision-making process (lesson 1: set realistic goals about research use);

- $\quad$ research but also academic expertise can be made accessible to decision makers (lesson 2: improve the supply of evidence but do not stop there);

- researchers and decision makers can work together to co-create evidence for decision making (lesson 3: shape as well as respond to the demand for evidence);

- the $\mathrm{KMb}$ Unit played a key role in brokering the relationship between researchers and the Municipality (lesson 5: recognise the role of dedicated knowledge brokers);

- many agencies, individuals and families, and policy makers were involved in the project (lesson 6: target multiple voices to increase opportunities for research use).

\section{Wider experience reported in the remainder of this Open Space section}

The three articles that follow this introductory one illustrate different approaches to using research knowledge in highly contrasting sectors and settings. These aim to further develop the discussion by opening the lid on what it is like to try to integrate research into policy or practice.

Coleman, Bauer, Houlston and Edwards discuss the way that academics and a voluntary organisation worked together to translate research findings so that they could be used by racially 'mixed' couples and their families. This raised awareness and developed services for this group. They report that enthusiasm and commitment from both partners was important in conducting the work, and that technical and staff support were crucial to success. Team members brought together a deeper understanding of the issues and the current context for 'mixed' families in the United Kingdom (UK).

Cunning, Muir, Golden and Rounthwaite explore the processes of integrating both external and internal research and evaluation data in a project to develop practice for an organisation supporting vulnerable children and families in Ontario, Canada. Starting from a clear understanding of the specific practice context and through leadership, support and integration, it successfully embedded a practice change process. The research translation task was shared between specialist evaluators and practitioners, and enthusiasm and leadership within teams were important elements of the project's achievements.

Steinerowski and Woovin aimed to embed research within a community change process around older people in rural communities. Here the researcher acted as a catalyst for change. They were embedded within the community and provided leadership and support for the change process as part of an action research project. Here research is integrated with the needs and demands of the community as they plan for and create new services and models of service delivery

Families, Relationships and Societies $\bullet$ vol I $・$ no $2 \cdot 2012 \cdot 243-53$

http://dx.doi.org/ | 0.1332/2046743 | 2 X645547 


\section{Looking to the future}

Interest in the impact of social research continues to receive attention from governments in the UK (ESRC, 2009; HEFC, 2009) and elsewhere. There remain a number of challenges for the future.

\section{Partnership and collaboration}

Partnership and collaborative approaches often lead to increased research use and impact, but these approaches are in their infancy. Both CRFR andYork University have pioneered partnership approaches, but there is limited research about these and what they mean for research uptake (Martin, 2010). The following articles explore partnerships between academics and the voluntary sector, with communities and service users. Partnerships seem promising but further investigation is needed into the effects of different kinds of collaboration on research agendas, research processes and research impact.

\section{New translation and communication methods}

There is enthusiasm for new information and communication technologies and their potential for improving research communication and interaction via virtual environments while also decreasing environmental impact. Improving the accessibility of research findings and opportunities for translation and discussion may be assisted by these new technologies. However, the reasons for interaction and the needs of the audience can often be lost in the excitement of using these technologies. The challenge is to develop effective new approaches that foster interaction, develop communication and provide virtual meeting spaces. York University's 'Mobilizing Minds: Pathways to Young Adult Mental Health' project has used a number of online tools to support collaboration and knowledge mobilisation, including blogs, Twitter, YouTube videos and an online collaboration platform. These kinds of examples are promising but there are still many challenges to get people to interact online in a meaningful way, and further evaluation is needed.

\section{Knowledge exchange in the recession}

Much of what we currently know about promising ways to promote research use and knowledge exchange has been fostered during a time of public spending growth, at least in the UK. How social research is viewed by policy makers and practitioners when budgets are shrinking and services are being cut remains to be seen. Steinerowski and Woolvin consider the implications of funding cuts for the role of the researcher engaged in a community development process, who needs to avoid creating expectations of new services while budgets on others are cut. Creativity and flexibility will be needed in order to illustrate the usefulness of research in this challenging climate. 


\section{Beyond the basics}

It has become much more common practice to offer standard methods of sharing research through better communication, increased accessibility and closer collaborations between academic research and interest groups in communities, policy or practice. There are still huge challenges for many research users in learning from research. Further work is needed on improving the knowledge-to-action process through experimentation with different methods and through academics being more responsive to research users' needs. Some ways in which this might be achieved are offered in the articles in this section.

\section{Valuing brokerage roles}

There is an increasing number of people in the university sector with knowledge brokerage roles and this has been key to the uptake of research in some cases. The challenge is how to get better recognition of the role and skills of knowledge brokering and other knowledge exchange support activities, while not stifling flexibility and creativity.This includes wider acknowledgement and visibility of the support needed for successful knowledge exchange.

\section{Learning and reflection}

Knowledge exchange practice has made great strides over the last 10 years, with many more programmes and centres with explicit knowledge exchange aims, and much experimentation and innovation. Methods for better planning and evaluation of knowledge exchange activities could build on this. The contributions in this Open Space section begin to set the agenda for this evaluation by reflecting on what seems to have worked and what has been more challenging.

\section{Final thoughts}

Making an impact with research is challenging at all times, and often beyond the control of the producers of that research. We know that research is used in many ways in both policy and practice, but its impact is often hidden from view and it may not always be possible to be aware of how it has had an impact. Understanding research 'use' as an interactive, social and political process means that engaging with it is not a simple or one-off affair. Researchers need to provide compelling ideas and persuasive evidence and engage in debate.

\section{Note}

${ }^{1}$ Corresponding author. 


\section{References}

Alexanderson, K., Beijer, E., Bengtsson, S., Hyvönen, U., Karlsson, P.-Å. and Nyman, M. (2009) 'Producing and consuming knowledge in social work practice: research and development activities in a Swedish context', Evidence $\&$ Policy: A Journal of Research, Debate and Practice, 5(2): 127-39.

Caplan, N. (1977) 'The use of social research knowledge at the national level', in C.H.Weiss (ed) Using social research in public policy making, Idaho Falls, ID: Lexington Books, 183-97.

Cousins, J.B. and Simon, M. (1996) 'The nature and impact of policy-induced partnerships between research and practice communities', Educational Evaluation and Policy Analysis, 18(3): 199-218.

Davies, H., Nutley, S. and Walter, I. (2008) 'Why "knowledge transfer" is misconceived for applied social research', Journal of Health Services Research \& Policy, 13(3): 188-90.

Davies, P. (2007) ‘Types of knowledge for evidence-based policy', NORFACE Seminar on Evidence and Policy, University of Edinburgh, 26 November.

ESRC (Economic and Social Research Council) (2009) Taking stock: A summary of ESRC'S work to evaluate the impact of research on policy and practice, Swindon: ESRC.

HEFC (Higher Education Funding Council) (2009) REF impact pilot guidance on submissions, www.hefce.ac.uk/research/ref/impact/

Martin, S. (2010) 'Co-production of social research: strategies for engaged scholarship', Public Money \& Management, 30(4): 211-18.

Mitton, C., Adair, C.E., McKenzie, E., Patten, S.B. and Waye, B. (2007) 'Knowledge transfer and exchange: review and synthesis of the literature', Milbank Quarterly, 85(4): 729-68.

Morton, S. (2011) Knowledge exchange at CRFR: Past, present, future, CRFR Research Briefing Series, Briefing 57, Edinburgh: Centre for Research on Families and Relationships.

Morton, S. and Nutley, S. (2011) 'What happens next? Getting research into policy and practice', in L.Jamieson, R. Lewis and R. Simpson (eds) Researching families and relationships: Reflections on process, New York, NY: Palgrave Macmillan.

Mullen, E.J. (2005) 'From concept to implementation: challenges facing evidence based social work', Evidence E Policy: A Journal of Research, Debate and Practice, 1(1): 61-84.

Nutley, S., Downe, J., Martin, S. and Grace, C. (2011) 'Policy transfer and convergence within the UK: the case of local government performance improvement regimes', Policy \& Politics, doi: http://dx.doi.org/10.1332/147084411X581880

Nutley, S., Walter, I. and Davies, H.T.O (2007) Using evidence: How research can inform public services, Bristol:The Policy Press.

Ouimet, M., Landry, R., Ziam, S. and Bédard, P.-O. (2009) 'The absorption of research knowledge by public civil servants', Evidence \& Policy: A Journal of Research, Debate and Practice, 5(4): 331-50.

Phipps, D. (2011) 'A report detailing the development of a university-based knowledge mobilization unit that enhances research outreach and engagement', Scholarly and Research Communication, 2(2): 020502,13pp.

Rein, M. (1976) Social science and public policy, Harmondsworth: Penguin Education.

Families, Relationships and Societies • vol I • no 2 • 2012 • 243-53

http://dx.doi.org/10.1332/2046743 I2X645547 
Singh, M. and Hynie, M. (2008) 'An evaluation of an inclusivity action plan', The International Journal of Diversity in Organisations, Communities and Nations, 8(4): $117-24$.

Ward, V., House, A. and Hamer, S. (2009) 'Developing a framework for transferring knowledge into action: a thematic analysis of the literature', Journal of Health Services Research E Policy, 14(3): 156-64.

Weiss, C.H. (1979) 'The many meanings of research utilisation', Public Administration Review, 39(5): 426-31.

Widmer,T. (2009) 'The contribution of evidence-based policy to the output-oriented legitimacy of the state', Evidence \& Policy: A Journal of Research, Debate and Practice, 5(4): 351-72.

\section{Sarah Morton}

Centre for Research on Families and Relationships, University of Edinburgh, and

Scottish School of Public Health Research, UK

s.morton@ed.ac.uk

\section{David Phipps}

Research Services and Knowledge Exchange, York University,

Toronto, Canada

\section{Sandra Nutley}

Research Unit for Research Utilisation,

University of Edinburgh Business School, UK 